\title{
Effect of HBx on inflammation and mitochondrial oxidative stress in mouse hepatocytes
}

\author{
LI-RONG LING* ${ }^{*}$ DAN-HUA ZHENG ${ }^{*}$, ZHI-YANG ZHANG, WEN-HUI XIE, \\ YUE-HONG HUANG, ZHI-XIN CHEN, XIAO-ZHONG WANG and DAN LI
}

\author{
Department of Gastroenterology, Fujian Medical University Union Hospital, Fuzhou, Fujian 350001, P.R. China
}

Received April 21, 2019; Accepted December 12, 2019

DOI: $10.3892 / 01.2020 .11404$

\begin{abstract}
Hepatitis B virus x protein (HBx) serves an important role in the pathogenesis of the hepatitis $\mathrm{B}$ virus infection. Previous studies have reported that the interaction between $\mathrm{HBx}$ and hepatocyte mitochondria is an important factor leading to liver cell injury and apoptosis, ultimately inducing the formation of liver cancer. In the present study, a mouse model expressing $\mathrm{HBx}$ was constructed using hydrodynamic in vivo transfection based on the interaction between HBx and cytochrome $c$ oxidase (COX) subunit III. The specific mechanism of HBx-induced oxidative stress in mouse hepatocytes and the subsequent effect on mitochondrial function and inflammatory injury was assessed. The results demonstrated that $\mathrm{HBx}$ reduced the activity of COX and the expression of superoxide dismutase and upregulated the expression of malondialdehyde, NF- $\mathrm{kB}$ and phospho-AKT, thus increasing oxidative stress. In addition, $\mathrm{HBx}$ induced an increase in interleukin (IL)-6, IL-1 $\beta$ and IL-18 expression levels, which created an inflammatory microenvironment in the liver, further promoting hepatocyte inflammatory injury. Therefore, it was proposed that HBx may affect hepatocyte mitochondrial respiration by reducing the activity of cytochrome $c$ oxidase, leading to mitochondrial dysfunction and inducing hepatocyte inflammation and injury.
\end{abstract}

\section{Introduction}

Chronic hepatitis B virus (HBV) infection is the leading cause of chronic hepatitis, cirrhosis and hepatocellular carcinoma (HCC) (1). At present, the mechanism by which HBV causes chronic hepatitis and liver cancer remains unclear; however, the hepatitis $B$ virus $\mathrm{x}(\mathrm{HBx})$ protein may serve a role in

Correspondence to: Professor Dan Li, Department of Gastroenterology, Fujian Medical University Union Hospital, 29 Xinquan Road, Gulou, Fuzhou, Fujian 350001, P.R. China

E-mail: doctorlidan@163.com

${ }^{*}$ Contributed equally

Key words: hepatitis $\mathrm{B}$ virus $\mathrm{x}$ protein, mitochondrion, oxidative stress, cytochrome $c$ oxidase, inflammation injury this process (1). HBx is a multifunctional regulatory protein composed of 154 amino acids, with a molecular weight of $17 \mathrm{kDa}$ (1). HBx is involved in a variety of signal transduction pathways affecting cell cycle progression, apoptosis and cancer progression (1). HBx can also affect mitochondria by altering the permeability of mitochondrial membranes, as HBx disrupts oxidative phosphorylation, interferes with the mitochondrial respiratory chain and inhibits ATP synthesis, leading to liver cell damage (2-6). Rahmani et al (2) have reported that HBx may be localized in the mitochondria, where it binds to the voltage-dependent anion channel 3 on the outer mitochondrial membrane, thus changing the mitochondrial membrane potential. Lee et al (3) have demonstrated that HepG2 cells that stably express HBx, causing the proton transfer to be blocked, induces the mitochondria of hepatocellular carcinoma cells in a sensitive state, thus leading to the formation of reactive oxygen species (ROS) and lipid peroxidation. Excessive ROS production then affects cell proliferation and differentiation, inducing apoptosis and gene mutations, thus promoting the occurrence of HCC. HBx can also induce the opening of the mitochondrial permeability transition pore and swelling of the mitochondrial matrix, mitochondrial membrane potential depolarization-induced release of cytochrome $c$ apoptosis-inducing factor and calcium ions into the cytoplasm, and apoptosis by activation of the caspase signaling cascade (4-6). The mitochondrial permeability transition pore and swelling of the mitochondrial matrix induce apoptosis or necrosis, lead to cytoplasmic calcium overload, enhance HBV replication and contribute to liver inflammation (4-6). In addition, HBx can also induce liver disease by activating autophagy, mitochondria-dependent apoptosis pathways, mitochondrial division and fusion damage $(7,8)$.

During the development of chronic hepatitis and cirrhosis, the mitochondrial respiratory chain is damaged and its function is significantly decreased (9). Cytochrome $c$ oxidase (COX), composed of 13 subunits including COXI, COXII and COXIII, which are encoded by mitochondrial DNA, serves a key role in oxidative phosphorylation $(10,11)$. The lack of functional order in COXIII hinders proton transfer and the accumulation of excess electrons and oxygen molecules leads to decreased ATP synthesis and mass ROS production $(10,11)$ during chronic hepatitis and cirrhosis. It has been reported that intracellular HBx is primarily localized in mitochondria $(12,13)$ 
and that HBx binds to COXIII, thereby upregulating ROS production (14-16).

Alterations in the levels of ROS in the mitochondria are common factors in the pathogenesis of inflammatory diseases and tumors (17). In acute liver inflammation, ROS primarily induces mitochondrial dysfunction through intracellular oxidative stress (17). Previous studies have demonstrated that the C-terminus of HBx causes mitochondrial DNA damage, resulting in the increase in ROS levels in liver cells. Accumulation of ROS can also upregulate HBx expression levels $(13,18)$, indicating that mitochondria are the primary targets of ROS.

The NF- $\kappa$ B/AKT signaling pathway is a key inflammatory pathway involved in the development of cancer. Abnormal activation of NF- $\mathrm{KB} / \mathrm{AKT}$ signaling in liver tissues can inhibit apoptosis and promote liver cell survival, which may lead to the development of liver cancer $(19,20)$. It has been reported that the NF-kB signaling pathway serves a role in ROS-mediated liver injury (21). In addition, previous studies have demonstrated that the PI3K/AKT signaling pathway is involved in $\mathrm{HBx}$-induced liver cancer formation and also serves a role in the regulation of antioxidant genes $(22,23)$.

Inflammatory mediators are the primary signal transducers in the tumor microenvironment and have been demonstrated to be involved in the development and progression of liver cancer. Numerous in vivo and in vitro studies have confirmed that the levels of inflammatory mediators, such as interleukin (IL)-6, IL-1 $\beta$, IL-10, tumor necrosis factor- $\alpha$ (TNF- $\alpha$ ) and transforming growth factor- $\beta$ (TGF- $\beta$ ) are often increased in the tissues and sera of patients with liver cancer (24-26). Pro-inflammatory IL-18 is involved in immune response regulation, and excessive IL-18 expression levels can lead to immune system deregulation, causing inflammatory damage to tissues and organs (27). The pro-inflammatory mediators (IL-6, IL-1 $\beta$, IL-10, TNF- $\alpha$, TGF- $\beta$ and IL-18) can promote tumor growth, inhibit apoptosis, induce epithelial-to-mesenchymal transition and ultimately promote the invasion and metastasis of liver cancer.

Increasing attention has drawn to the relationship between malondialdehyde (MDA), superoxide dismutase (SOD) and mitochondria. Several studies on drugs (such as the impairment of mitochondrial function in mice with a low or excessive selenium diet) and the pathogenesis of diseases (for example, liver dysfunction) have been conducted by measuring the expression levels of MDA and SOD and observing the structural changes in mitochondria and demonstrating their association $(28,29)$. Paradies et al $(30)$ reported that decreased COX activity of myocardial mitochondria in rats was associated with increased lipid oxidation levels caused by increased MDA activity. Therefore, changes in MDA and SOD levels in the serum may reflect the state of mitochondria and indicate the degree of liver cell damage.

In the present study, a mouse model expressing HBx was established to observe acute hepatocyte injury in mice, and the levels of IL-6, IL-1 $\beta$, IL-18, MDA and SOD and COX activity were determined. Changes in ROS levels, NF- $\kappa \mathrm{B}, \mathrm{AKT}$ and phosphorylated (p-) AKT were measured. The mechanism by which HBx affects mitochondrial function in hepatocytes, induces inflammation and damages hepatocytes was explored in vivo, providing new insight into the mechanism underlying HBV-related chronic hepatitis and hepatocellular carcinoma.

\section{Materials and methods}

Animals. The present study was approved by The Institutional Animal Care and Use Committee of Fujian Medical University (Fujian, China). Mice were euthanized using an intraperitoneal injection of $2 \%$ sodium pentobarbital at a dose of $100 \mathrm{mg} / \mathrm{kg}$ and death was confirmed by observing the ventilation, complete cardiac arrest and loss of reflexes. A total of 30 male ICR mice, aged 6-8 weeks and weighing 19-22 g, were purchased from Shanghai SLAC Laboratory Animal Technology Co. Ltd. The mice were maintained at $25^{\circ} \mathrm{C}$ with a $12: 12 \mathrm{~h}$ light/dark cycle and were provided with food and water, and access to food and water was arbitrary. The mice were randomly divided into 3 groups ( $n=10$ per group) based on the administered treatment: i) Experimental; ii) null-plasmid control; and iii) blank control (plasmid solvent) groups. The solutions were injected into the caudal vein under high pressure.

Preparation of competent bacteria. E. coli $\mathrm{DH} 5 \alpha$ cells from Tiangen Biotech Co., Ltd. were cultured on agar plates at $37^{\circ} \mathrm{C}$ in an incubator overnight. A single colony was collected from the plate and the cells were cultured further with agitation at $37^{\circ} \mathrm{C}$ and $250 \mathrm{rpm}$ for $12 \mathrm{~h}$. Subsequently, the bacteria were incubated on ice for $30 \mathrm{~min}$ followed by centrifugation at $4,000 \mathrm{x} \mathrm{g}$ and for $10 \mathrm{~min}$ at $4^{\circ} \mathrm{C}$. The supernatant was discarded, and $1 \mathrm{ml}$ precooled $0.1 \mathrm{~mol} / \mathrm{C} \mathrm{CaCl}_{2}$ was added to the obtained pellet. The mixture was mixed with a pipette.

Plasmid transformation and extraction. pcDNA3.1-HBx plasmid (stored in the laboratory) was added to a $200-\mu 1$ suspension of susceptible $E$. coli DH5 $\alpha$ cells, mixed by shaking gently, placed on ice for $30 \mathrm{~min}$, subjected to heat shock at $42^{\circ} \mathrm{C}$ for $2 \mathrm{~min}$, and quickly moved to ice for 3-5 min. The cells were added to $800 \mu 1 \mathrm{LB}$ medium and cultured with agitation at $37^{\circ} \mathrm{C}$ and $250 \mathrm{rpm}$ for $1 \mathrm{~h}$. Bacterial cells were then streaked onto liquid culture medium using inoculation loops, followed by incubation of the plates at $37^{\circ} \mathrm{C}$ for $18-24 \mathrm{~h}$. The transformed bacteria were followed by plasmid extraction using an EndoFree Plasmid Maxi kit (Qiagen, Inc.).

RNA extraction and reverse transcription PCR analysis. Total RNA from mouse liver tissue was extracted using TRIzol ${ }^{\circledR}$ reagent (Invitrogen; Thermo Fisher Scientific, Inc.). Total RNA $(2 \mu \mathrm{g})$ was reverse-transcribed into cDNA using a RevertAid First Strand cDNA Synthesis kit (Thermo Fisher Scientific, Inc.). The conditions for the RT of RNA into DNA were as follows: $60 \mathrm{~min}$ at $42^{\circ} \mathrm{C}, 5 \mathrm{~min}$ at $70^{\circ} \mathrm{C}$, and storage at $4^{\circ} \mathrm{C}$. The primer sequences of each gene are listed in Table I. The thermo cycling conditions of PCR were as follows: Pre-denaturation at $95^{\circ} \mathrm{C}$ for $5 \mathrm{~min}$; followed by 30 cycles of denaturation at $95^{\circ} \mathrm{C}$ for $30 \mathrm{sec}$, annealing at $62^{\circ} \mathrm{C}$ for $30 \mathrm{sec}$ and $72^{\circ} \mathrm{C}$ for $1 \mathrm{~min}$; and a final extension step at $72^{\circ}$ for $7 \mathrm{~min}$. PCR was performed using a Taq PCR Master mix (Thermo Fisher Scientific, Inc.). A total of $10 \mu \mathrm{l} \mathrm{PCR} \mathrm{product} \mathrm{with} 5 \mu \mathrm{l}$ marker (cat. no. MD110; Tiangen Biotech Co., Ltd.) was loaded onto a $2 \%$ agarose gel containing $1.5 \mu \mathrm{l}$ gold view (Beijing Solarbio Science \& Technology Co., Ltd.). Gel electrophoresis was performed at $100 \mathrm{~V}$ for 15-30 $\mathrm{min}$. The results of the electrophoresis were scanned using a UVP scanner with Grab-IT 
Table I. Primer sequences.

\begin{tabular}{l}
\hline Gene \\
\hline HBx-flag \\
Forward ATGCAAGCTTATGGCTGCTAGGCTGTACTG $\left(5^{\prime} \rightarrow 3^{\prime}\right)$ \\
Reverse TGCGAATTCTTAGGCAGAGGTGAAAAAGTT \\
$\beta$-actin \\
Forward GGCATCGTGATGGACTCCG \\
Reverse GCTGGAAGGTGGACAGCGA
\end{tabular}

$\mathrm{HBx}$, hepatitis B x protein.

(Gel Doc 100; Bio-Rad Laboratories, Inc.) and analyzed by Gelpro32 (Media Cybernetics, Inc.).

Western blot analysis. Liver tissues were lysed in RIPA buffer (Beyotime Institute of Biotechnology) supplemented with protease inhibitors (Beyotime Institute of Biotechnology) and kept on ice for $30 \mathrm{~min}$, followed by centrifugation at $12,000 \mathrm{x} \mathrm{g}$ for $15 \mathrm{~min}$ at $4^{\circ} \mathrm{C}$. Protein concentration was measured using a Bicinchoninic Acid (BCA) Protein Assay kit (Beyotime Institute of Biotechnology). Total protein samples $(60 \mu \mathrm{g})$ were loaded onto a $12 \%$ gel, resolved using SDS-PAGE, transferred to a nitrocellulose filter membrane and blocked with 5\% non-fat milk in Tris-buffered saline containing $0.1 \%$ Tween-20 (TBST) for $60 \mathrm{~min}$ at room temperature. The membranes were incubated overnight at $4^{\circ} \mathrm{C}$ with the following primary antibodies: Rabbit anti-human HBx (1:1,000; cat. no. ab39716; Abcam), rabbit anti-mouse NF-кB (1:1,000; cat. no. 8242; Cell Signaling Technology, Inc.), rabbit anti-mouse AKT (1:1,000; cat. no. 4685; Cell Signaling Technology, Inc.), rabbit anti-mouse p-AKT (1:500; cat. no. 4060; Cell Signaling Technology, Inc.) and rabbit anti-mouse GAPDH (1:1,000; cat. no. 2118; Cell Signaling Technology, Inc.). The membrane was then washed three times (10 min each) with TBST and incubated with a goat anti-rabbit horseradish peroxidase-conjugated secondary antibody (1:5,000; cat. no. ZB-2301; OriGene Technologies, Inc.) for $60 \mathrm{~min}$ at room temperature. After washing with TBST, the membrane was incubated with an ECL chemiluminescence kit (1:1; OriGene Technologies, Inc.) for $1 \mathrm{~min}$. A auto-exposure (ChemiDoc MP System; Bio-Rad Laboratories, Inc.) was used to expose the target strip and analyzed by Gelpro32.

Construction and identification of a HBx expression mouse model. Hydrodynamics-based transfection is an in vivo gene transfection method based on the principle of making the venous system and hepatic sinus of mice hyperemic and generating high venous pressure, which permits the transfer of plasmids into liver cells by rapidly injecting a large volume of plasmid solution into the tail vein $(31,32)$. The present study used this method to transfect mice with pcDNA3.1-HBx, empty pcDNA3.1 plasmids and plasmid solvent, according to the manufacturer's protocol using a TransIT In Vivo Gene Delivery system (Mirus Bio). A total of $\sim 250 \mu \mathrm{g}$ of plasmid was added to the in vivo polymer solution in a $15-\mathrm{ml}$ centrifuge tube that does not contain nucleotide enzymes, and the tube was allowed to stand at room temperature for $5 \mathrm{~min}$. The solution was then injected into the mice via the caudal vein at a constant speed within 4-8 sec. After $24 \mathrm{~h}$, the mice were euthanized and eyeball blood and liver tissues were collected; eyeball blood was stored at $-20^{\circ} \mathrm{C}$, and liver tissue was cryopreserved at $-70^{\circ} \mathrm{C}$.

Isolation of mitochondria and measurement of COX activity. Mitochondria were isolated using the Mitochondrial Isolation kit (Beyotime Institute of Biotechnology) according to the manufacturer's instructions. Following lysis of $\sim 100 \mathrm{mg}$ of liver tissue, cell debris and nuclei were removed by centrifugation at $700 \mathrm{xg}$ for $10 \mathrm{~min}$ at $4^{\circ} \mathrm{C}$, followed by centrifugation at $3,000 \mathrm{xg}$ for $15 \mathrm{~min}$ at $4^{\circ} \mathrm{C}$ to pellet the mitochondria-enriched fraction and then at $12,000 \mathrm{x}$ g for $5 \mathrm{~min}$ at $4^{\circ} \mathrm{C}$ to pellet the isolated mitochondria. Protein concentrations were measured using the BCA Assay kit (Beyotime Institute of Biotechnology) and adjusted to $1 \mu \mathrm{g} / \mu 1$. COX activity was determined using the Cytochrome $c$ Oxidase Assay kit (Genmed Scientifics Inc,) according to the manufacturer's instructions and measured by an ELx800 microplate reader (BioTek Instruments Inc.) at $550 \mathrm{~nm}$.

In situ fluorescence assay for reactive oxygen species measurement. In situ fluorescence staining was used to detect the ROS levels in the frozen sections of mouse liver tissue. Frozen sections $(10 \mathrm{~mm})$ were stained using a ROS in situ fluorescence staining kit (GenMed) and placed at room temperature. Briefly, the section surface was covered with $500 \mu \mathrm{l}$ pre-cooled cleaning solution, which was then carefully removed. Subsequently, $200 \mu \mathrm{l}$ staining and diluent dye solutions were carefully added to cover the section surface, and the sections were incubated at $37^{\circ} \mathrm{C}$ for $30 \mathrm{~min}$. The sections were treated again with $500 \mu 1$ of pre-cooled cleaning solution after removal of the other reagents, followed by removal of the pre-cooled cleaning solution. The sections were then transferred to glass slides, covered and observed under a Nikon Eclipse TE 2000-U inverted fluorescence microscope at x100 magnification (Nikon Corporation); enhanced green fluorescence was observed at $499 \mathrm{~nm}$ excitation and $515 \mathrm{~nm}$ emission wavelengths.

$H \& E$ staining. The control group and the experimental group model mice were injected with pcDNA3.1-HBx, empty pcDNA3.1 plasmids and plasmid solvent solution into the tail vein for $24 \mathrm{~h}$, and liver tissues sized $1.0 \times 1.0 \times 0.3 \mathrm{~cm}$ were obtained, fixed with $4 \%$ paraformaldehyde for $24 \mathrm{~h}$ at room temperature. Subsequently, the tissue sections were dehydrated in 80, 90, 95 and $100 \%$ gradient ethanol for 2-4 h. The embedded liver tissue was cut into $3-\mu \mathrm{m}$ sections, using the microtome (Thermo Fisher Scientific, Inc.), and dried for H\&E staining. Following $20 \mathrm{~min}$ of baking at $60^{\circ} \mathrm{C}$, xylene I and II were used to dewax the tissues for $10 \mathrm{~min}$ each. Subsequently, tissues were incubated in $100,95,85,75 \%$ gradient ethanol for $5 \mathrm{~min}$ each, and in distilled water for $5 \mathrm{~min}$ to complete the dewaxing process. Hematoxylin (cat. no. C0390; Beijing Noblelight Technology Co., Ltd.) staining was performed for $5 \mathrm{~min}$ at room temperature, after washing with water. Eosin staining (cat. no. C0390, NobleRyder) was conducted for $5 \mathrm{sec}$, and the sections were subsequently fully washed (33). 
Sections were then dehydrated using 75, 85, 95 and $100 \%$ ethanol (2 min each). Xylene I, II transparent for 5 min neutral gum seal is intended for fixation. Sections were observed and images were captured using a Leica DM2000 light microscope (Leica Microsystems, Inc.; magnification, x20).

Detection of MDA, SOD, $I L-6, I L-1 \beta$ and $I L-18$ in serum. Inflammatory cytokine expression in mouse serum was detected using mouse ELISA kits (Mouse MDA/SOD/IL-6/IL-1 $\beta / \mathrm{IL}-18$ ELISA kits; cat. nos. M6000B, DYC3419-2, 7625, MLB00C; $\mathrm{R} \& \mathrm{D}$ Systems, Inc.). The serum was thawed at room temperature and thoroughly mixed. A wash buffer diluted 1:20 with distilled water was used. In the ELISA plate, the wells were divided into standard, sample and blank wells. A total of $50 \mu 1$ of the different concentrations of the standard (10 $\mu \mathrm{l}$ of the test sample and $40 \mu \mathrm{l}$ of the diluent) were added to the standard and sample wells, respectively. Nothing was added to the blank well. Subsequently, $100 \mu \mathrm{l}$ of the horseradish peroxidase-labeled detection antibody was added to the standard and sample wells. The reaction plate membrane aperture was sealed, and the plate was incubated at $37^{\circ} \mathrm{C}$ for $60 \mathrm{~min}$. After the incubation period, unbound components were discarded, and the plate was patted dry with absorbent paper. The wells were filled with washing liquid, and the plate was allowed to rest for $1 \mathrm{~min}$. The washing liquid was then discarded, and the plate was patted dry with absorbent paper. The substrates (50 $\mu \mathrm{l}$ each) were added, and the plate was incubated at $37^{\circ} \mathrm{C}$ in the dark for $15 \mathrm{~min}$, followed by the addition of $50 \mu \mathrm{l}$ termination solution to each well for $15 \mathrm{~min}$. The optical density was measured at $450 \mathrm{~nm}$ using an ELx800 microplate reader (BioTek Instruments, Inc.).

Statistical analysis. Data were analyzed using GraphPad Prism statistical software version 5.0 (GraphPad Software, Inc.) and ImageJ 2x (National Institutes of Health). Data are expressed as the mean \pm standard deviation (unless otherwise stated) from at least three independent experiments. One-way ANOVA was used for statistical analysis, followed by Tukey's post hoc test to assess statistical differences among groups. $\mathrm{P}<0.05$ was considered to indicate a statistically significant difference.

\section{Results}

Transfection efficiency. Transfection of pCDNA3.1-HBx notably increased the mRNA (Fig. 1A) and protein (Fig. 1B) expression levels in mouse liver tissues. $\mathrm{HBx}$ expression was not observed in the control or empty vector-transfected liver tissues. These results demonstrated that the HBx gene was successfully transfected into the livers of experimental mice.

Effect of HBx on the mitochondrial function in mouse hepatocytes. MDA levels in serum of mice in the experimental group transfected with pcDNA3.1-HBx were significantly higher compared with the control group and mock group, whereas SOD levels were significantly lower compared with the control group and mock group $(\mathrm{P}<0.01$; Fig. $2 \mathrm{~A})$.

The detection of COX using enzymatic kinetics demonstrated that COX activity in the experimental group transfected with pcDNA3.1-HBx was significantly lower compared with
A

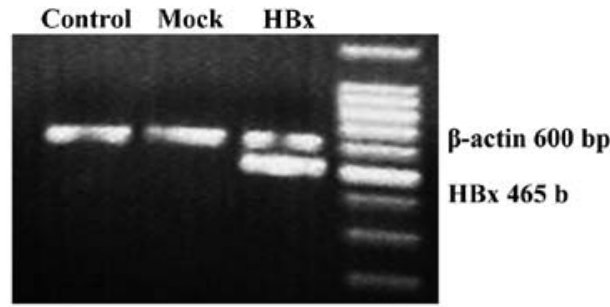

B
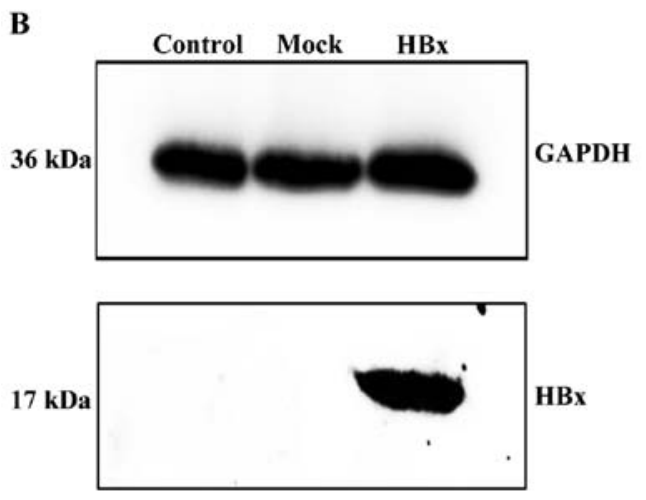

Figure 1. Identification of $\mathrm{HBx}$ expression in the mouse model. (A) mRNA and (B) protein expression levels of HBx. Control, blank control group treated with plasmid solvent; Mock, null plasmid control group; HBx, experimental group; M, marker; HBx, hepatitis B virus x protein.

in the control group and mock group $(\mathrm{P}<0.001$; Fig. 2B), indicating that COX activity was reduced by $\mathrm{HBx}$, which was in agreement with our previous experimental results in HL-7702 cells stably expressing HBx (15).

Oxidative stress was determined by measuring the ROS levels in frozen sections using in situ fluorescence staining. In the experimental HBx group, compared with the pcDNA3.1 plasmid-transfected group and the control group, the ROS levels in the liver tissues were significantly increased $(\mathrm{P}<0.05$; Fig. 2C and D).

ROS-mediated effects of $H B x$ on $N F-\kappa B$ and $p$-AKT expression in mouse hepatocytes. The results of western blot analysis demonstrated that the expression levels of NF- $\mathrm{KB}$ and p-AKT were significantly increased in the experimental HBx group, which was significant compared with the empty plasmid group and the blank group $(\mathrm{P}<0.01$; Fig. 3$)$.

Detection of HBx-induced inflammatory damage in hepatocytes. Edema and inflammatory cell infiltration were observed in the liver tissue of the HBx group by HE staining (Fig. 4). The serum levels of the inflammatory cytokines IL-6, IL-1 $\beta$ and IL-18 in the experimental group were significantly higher compared with the control group and mock group $(\mathrm{P}<0.001$; Fig. 5A-C). This indicated that HBx may induce the synthesis and secretion of IL- 6, IL- $1 \beta$ and L-18, thus promoting inflammatory damage in liver cells.

\section{Discussion}

Under normal physiological conditions, ROS levels are in a stable state, and their production and clearance maintain a certain dynamic balance. When the body is invaded by bacteria 

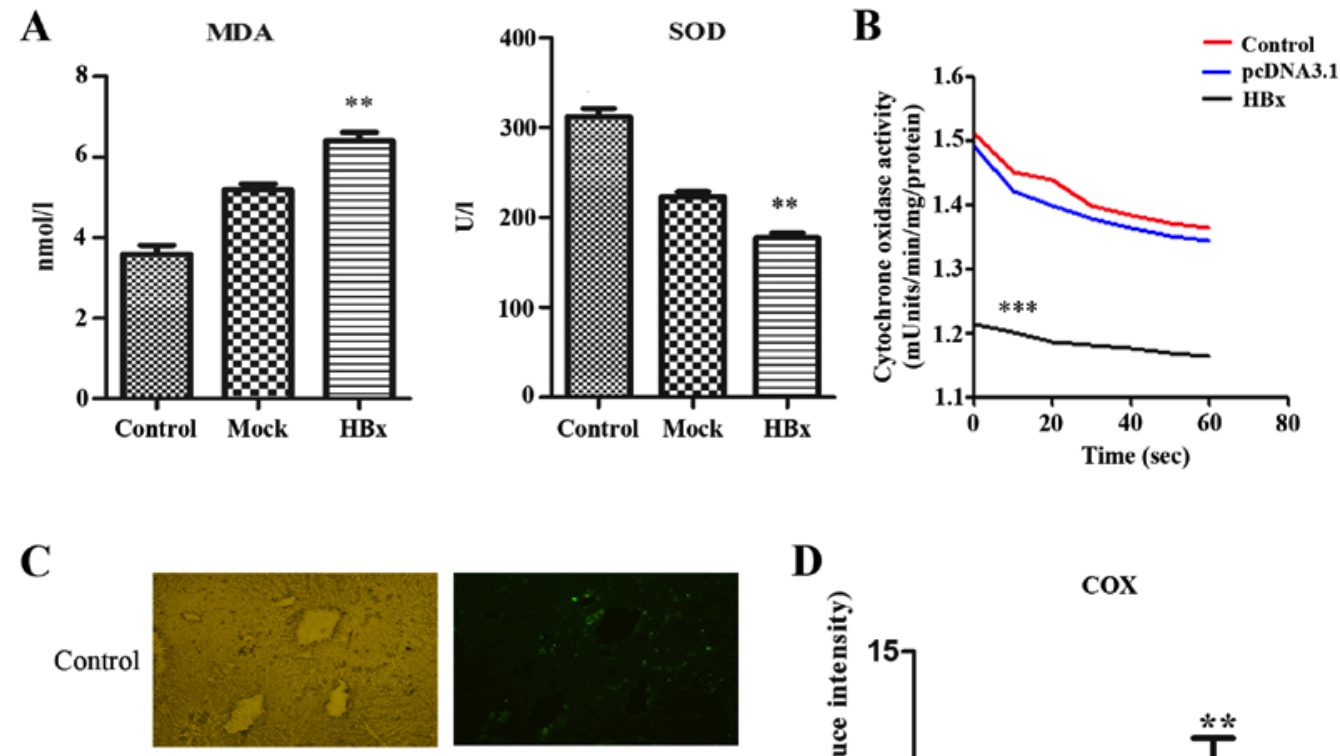

D
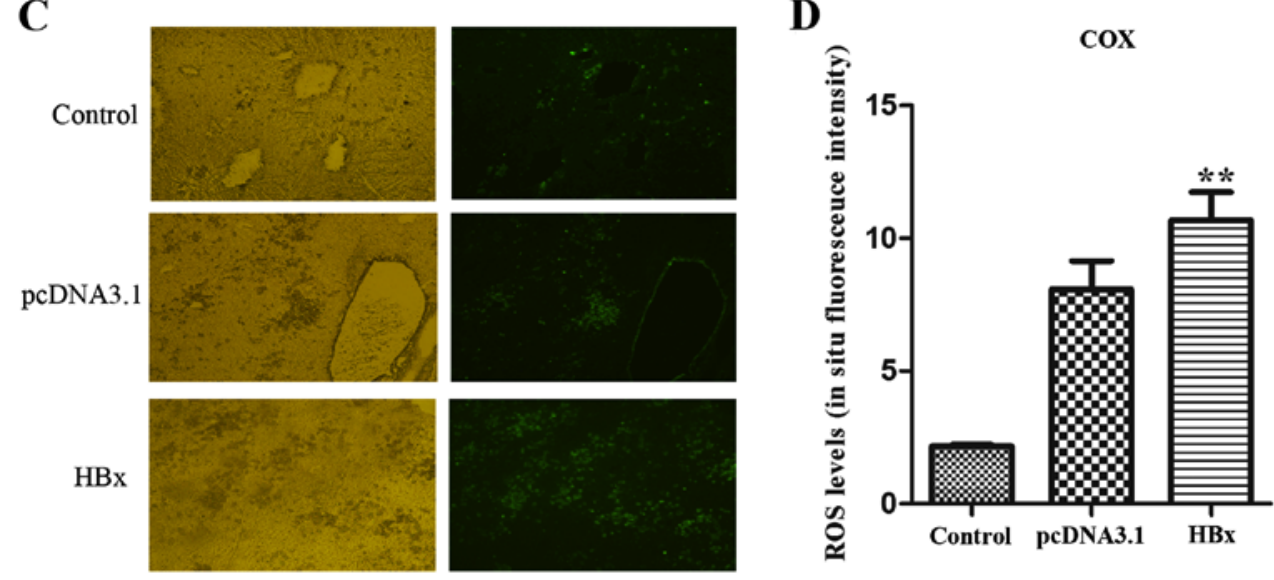

Figure 2. Effect of HBx on mitochondrial function in mouse hepatocytes. (A) Changes in oxidative stress and COX in the sera of mice demonstrated that HBx significantly increased MDA and decreased SOD levels in the sera of mice. $n=10$. ${ }^{* *} \mathrm{P}<0.01$ vs. Control; (B) HBx reduced COX levels. $n=10 .{ }^{* * * *} \mathrm{P}<0.001$ vs. Mock. (C) and (D) HBx increased ROS levels in liver tissues observed by fluorescence microscopy. Magnification, $\mathrm{x} 100$. ${ }^{* *} \mathrm{P}<0.01 \mathrm{vs}$. Control and Mock. Control, blank control group treated with plasmid solvent; Mock, null plasmid control group; HBx, experimental group; HBx, hepatitis B virus x protein; MDA, malondialdehyde; SOD, superoxide dismutase; COX; Cytochrome c oxidase.
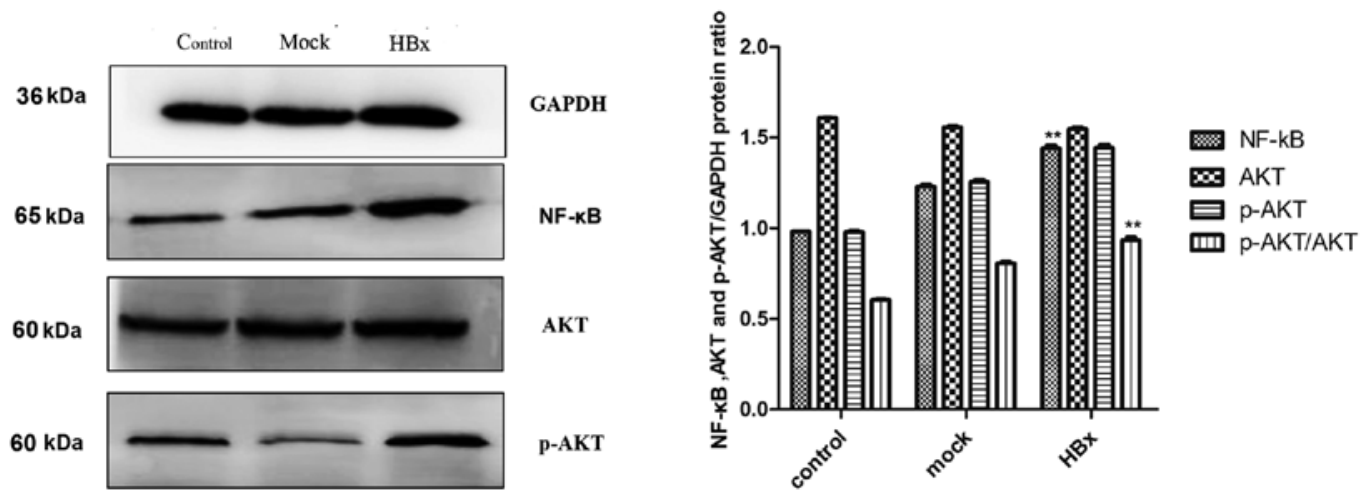

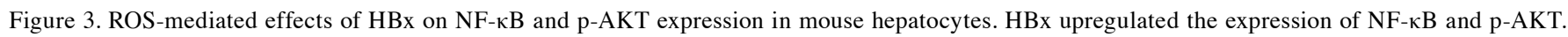
${ }^{* *} \mathrm{P}<0.01$ vs. Control and Mock. Control, blank control group treated with plasmid solvent; Mock, null plasmid control group; HBx, experimental group; $\mathrm{HBx}$, hepatitis B virus x protein; $\mathrm{kDa}$, kilodaltons; $\mathrm{p}-\mathrm{AKT}$, phosphor-AKT.

or viruses, ROS are actively produced as part of the immune response. Another major source of ROS production is the oxidative metabolism of mitochondria. The increase in ROS levels can affect cell signaling pathways and cell growth (34). In particular, ROS influences the NF- $\kappa \mathrm{B}$ signaling pathway and activates the MAPK and STAT3 signaling pathways via the release of IL-1 $\beta$, IL- 6 and TNF- $\alpha$ (35-37). However, excessive production of inflammatory cytokines induced by HBx can stimulate cells to produce a large amount of ROS, further stimulating NF- $\mathrm{kB}$ to produce inflammatory mediators (for example: IL-1 $\beta$, IL-6 and TNF- $\alpha$ ), forming a cycle and thus accelerating the inflammatory injury of liver cells and HBV replication (37).

Previous studies have demonstrated that the HBx protein interacts with the mitochondrial COXIII subunit, causing mitochondrial damage and affecting the biological activity of liver cells (14-16). In the present study, HBx was demonstrated to alter the mitochondrial oxidative respiratory chain 

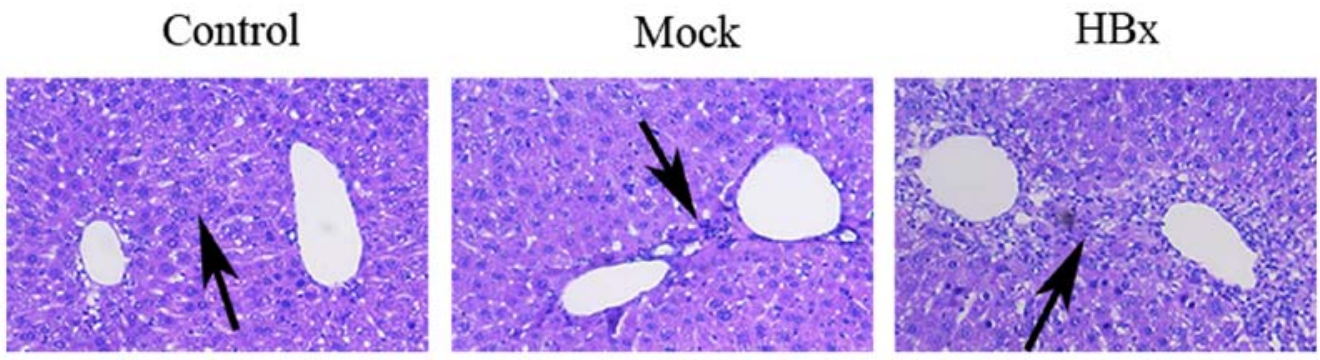

Figure 4. Hepatocyte inflammatory injury mediated by HBx. HBx promoted inflammatory damage in liver cells, and edema and inflammatory cell infiltration were observed in the liver tissue of the HBx experimental group. Shown by black arrow. Magnification, x20. Control, blank control group treated with plasmid solvent; Mock, null plasmid control group; HBx, experimental group; HBx, hepatitis B virus x protein.

A

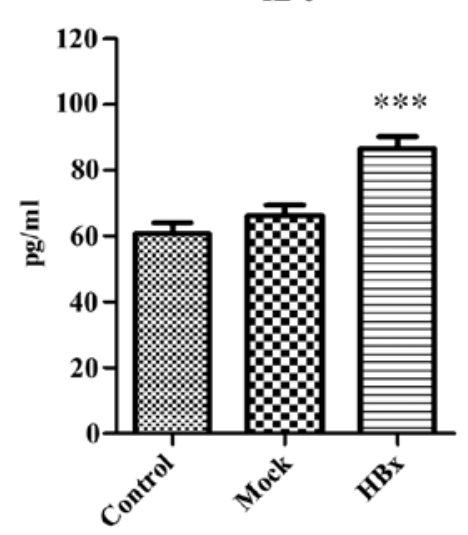

B

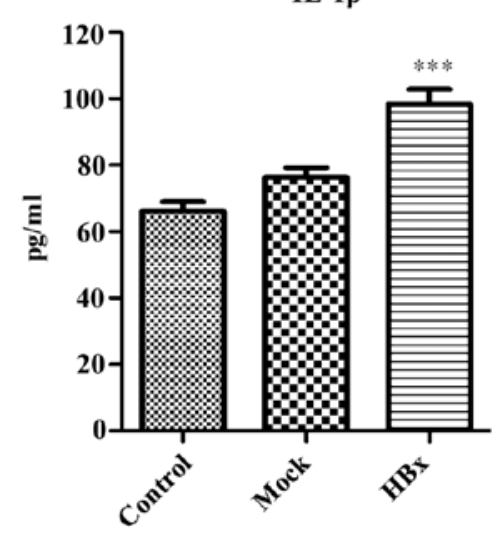

C

IL-18

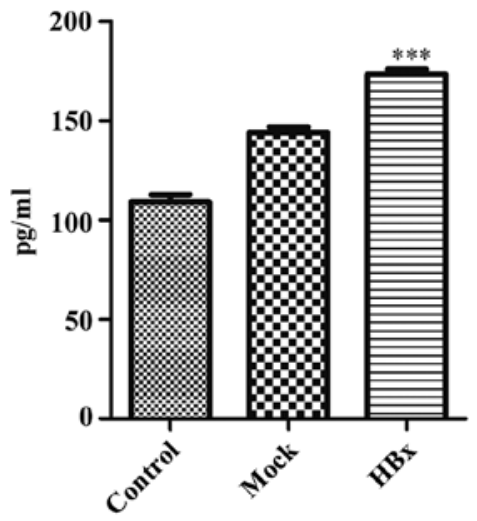

Figure 5. HBx induces the expression of pro-inflammatory cytokines IL-6, IL-1 $\beta$ and IL-18. (A) HBx promoted a significant increase in IL-6 levels in the sera of mice $(n=10) .{ }^{* * *} \mathrm{P}<0.001$ vs. Control and Mock. (B) HBx increased the levels of IL-1 $\beta$ in the sera of mice. $n=10$. ${ }^{* * *} \mathrm{P}<0.001$ vs. Control and Mock. $(\mathrm{C}) \mathrm{HBx}$ increased IL-18 levels in the sera of mice. $\mathrm{n}=10$. ${ }^{* * * *} \mathrm{P}<0.001$ vs. Control and Mock. Control, blank control group treated with plasmid solvent; Mock, null plasmid control group; HBx, experimental group; IL, interleukin.

activity by reducing COX activity, that was in agreement with our previous experimental results in HL-7702 cells stably expressing HBx (15). This resulted in altered intracellular ROS levels and increased expression levels of NF- $\kappa B$ and p-AKT. Therefore, HBx may have increased NF- $\mathrm{kB}$ protein expression levels, which subsequently promoted an increase in hepatocyte ROS levels, thus damaging hepatocytes (37). HBx may also upregulate p-AKT protein expression levels as a mechanism to minimize oxidative damage in hepatocytes, although it was observed in this study that the antioxidant effect of p-AKT was insufficient to reverse the liver damage caused by HBx. However, HBx-induced upregulation of MAPK, NF- $\mathrm{KB}$ and PI3K is considered an important factor in the development of HCC $(34,38,39)$, and abnormal activation of NF- $\mathrm{KB}$ in liver cancer tissue has been reported to inhibit apoptosis and promote liver cell proliferation, contributing to cancer development (38).

Previous studies have demonstrated that the PI3K/AKT pathway serves a role in $\mathrm{HBx}$-induced $\mathrm{HCC}$ formation and the activation of nuclear factor erythroid 2-related factor 2 (NRF2), a key transcription factor regulating antioxidant genes during oxidative stress and maintaining intracellular redox homeostasis $(40,41)$. In addition, SOD is a protease that scavenges for excess oxygen free radicals, serving a role in maintaining the generation and scavenging balance of oxygen free radicals. Therefore, the decreased serum levels of SOD observed in experimental mice of the present study supported the notion that the antioxidant capacity in the HBx group was enhanced.

Previous studies have demonstrated that, under oxidative stress, NRF2/ARE can induce the expression of cell protective genes in HBV-positive cells $(40,42)$. Papaiahgari et al (40) have confirmed that ROS activates NRF2 via the PI3K/AKT signaling pathway. Increased ROS activates mitotic pathways through oxidative inactivation of PTEN, a tumor suppressor that serves a role in AKT dephosphorylation, therefore permitting AKT phosphorylation and activation and accelerating HepG2 cell growth, which is closely associated with the development of liver cancer in HBx transgenic mice (43). The increased expression of NF- $\mathrm{KB}$ and $\mathrm{p}-\mathrm{AKT}$ in the experimental group of the present study indicated that the NF- $\mathrm{KB}$ and AKT signaling pathways may serve a role in ROS-mediated HBx-induced inflammatory hepatocyte injury. The present study demonstrated that the expression levels of $\mathrm{NF}-\kappa \mathrm{B}$ and $\mathrm{p}-\mathrm{AKT}$ were increased in the experimental group; in addition, the expression levels of NF- $\mathrm{KB}$ and $\mathrm{p}-\mathrm{AKT}$ in liver cells were significantly decreased following treatment with ROS inhibitors (data not shown). These results suggested that $\mathrm{HBx}$ may activate NF- $\mathrm{KB}$ and AKT signaling through multiple pathways mediated by ROS. Therefore, ROS may serve an important role in HBX-induced hepatocyte inflammatory injury. 
During HBV infection, the immune response may lead to liver cell injury as, HBx increases the expression of MHC-I and MHC-II by activating MHC promoters and forming of HBx-MHC antigen-peptide complexes, which ultimately activate cellular and humoral immune responses, respectively (44). Lara-Pezzi et al $(45,46)$ have demonstrated that HBx upregulates the expression levels of TNF- $\alpha$ in hepatocytes by activating the nuclear factor of activated $\mathrm{T}$ cells in the cellular immune response. TNF- $\alpha$ mediates the activation of $\mathrm{CD}^{+}$cytotoxic $\mathrm{T}$ cells, which eliminates infected cells by releasing toxic particles and activating death receptor pathways. In addition, $\mathrm{CD} 8^{+}$cytotoxic $\mathrm{T}$ lymphocytes may damage the membranes of liver cells, which results in liver cell injury and initiates apoptosis.

A previous study has demonstrated that HBx stimulates the synthesis and secretion of IL-6, a major pro-inflammatory cytokine, in a toll-like receptor adaptor protein myeloid differentiation factor 88 (MYD88)-dependent manner (47). Quétier et al (48) reported that HBx transgenic mice overexpressed IL-6, increased hepatic proliferation and delaying hepatocyte regeneration. A possible explanation for this may be that HBx also activates signaling proteins downstream of MYD88, including NF- $\mathrm{B}$, which was upregulated in the experimental group of the present study and may have contributed to hepatocyte injury (47).

$\mathrm{HBx}$ selectively regulates other pro-inflammatory cytokines, such as IL-1 $\beta$, IL-18 and IL-23, and participates in the regulation of immune cell interactions $(49,50)$. These cytokines serve a role in the development and progression of liver cancer. IL-1 $\beta$ promotes neutrophil migration to the liver, phagocytosis and pathogen elimination, regulates tumor growth and is associated with the invasion and metastasis of liver cancer $(51,52)$. In addition, Chen et al (38) have demonstrated that $\mathrm{HBx}$ increases IL-1 secretion and induces NF-kB activation by interacting with an evolutionarily-conserved signaling intermediate in the Toll pathway. IL-18 is a pro-inflammatory cytokine that mediates the inflammatory cascade reaction and is a factor in acute liver injury (53). IL-18 levels in the sera of patients with hepatocellular carcinoma are significantly increased, which suggests that HBx may promote the occurrence and development of hepatocellular carcinoma by regulating IL-18 $(53,54)$. Overall, these studies suggest that pro-inflammatory cytokines serve a role in HBx-induced hepatic inflammatory injury.

In the present study, $\mathrm{H} \& \mathrm{E}$ staining of liver tissue and the levels of IL-6, IL-1 $\beta$ and IL-18 in the sera of the experimental group demonstrated that edema and inflammatory cell infiltration had occurred in the central part of the portal tissue. The levels of IL-6, IL-1 $\beta$ and IL-18 were also significantly higher compared with the control group. In addition, HBx increased the expression levels of TNF- $\alpha$, receptor-interacting protein kinase (RIP)3 mRNA and RIP3 protein (date not shown). This was consistent with the results from a previous study, which demonstrated that TNF- $\alpha$ activates RIP3, inducing programmed necrosis of cells and aggravating cellular inflammatory responses (data not shown).

In summary, the present study demonstrated that $\mathrm{HBx}$ upregulated the expression levels of IL-6, IL-1 $\beta$ IL-18, NF-kB and $\mathrm{p}-\mathrm{AKT}$, increased the level of oxidative stress and ultimately contributed to an inflammatory microenvironment in the liver. HBx reduced the activity of COX and may affect mitochondrial respiration in liver cells, resulting in mitochondrial dysfunction and subsequent inflammatory damage of liver cells.

\section{Acknowledgements}

Not applicable.

\section{Funding}

The present study was supported by The Fujian Natural Science Foundation (grant no. 2018J01314), The Fujian Province Health and Family Planning Research Talent Training Project (grant no. 2018-CX-21) and The Joint Funds for the Innovation of Science and Technology (grant no. 2017Y9048).

\section{Availability of data and materials}

The datasets used and/or analyzed during the current study will be provided by the corresponding author on reasonable request.

\section{Authors' contributions}

DL designed the experiments. LL and DZ performed the experiments and wrote the manuscript. ZZ, WX, ZC, YH and $\mathrm{XZ}$ analyzed the experimental results.

\section{Ethics approval and consent to participate}

The present study was approved by The Institutional Animal Ethics Committee of Fujian University of Medicine.

\section{Patient consent for publication}

Not applicable.

\section{Competing interests}

The authors declare that they have no competing interests.

\section{References}

1. Martín-Vílchez S, Moreno-Otero R and Sanz-Cameno P; Grupo CIBERehd de Hepatología del Hospital Universitario de La Princesa: Effects of hepatitis B virus X protein on chronic hepatitis B pathophysiology. Med Clin (Barc) 140: 508-513, 2012 (In Spanish).

2. Rahmani Z, Huh KW, Lasher R and Siddiqui A: Hepatitis B virus $X$ protein colocalizes to mitochondria with a human voltage-dependent anion channel, HVDAC 3 , and alters its transmembrane potential. J Virol 74: 2840-2846, 2000.

3. Lee YI, Hwang JM, Im JH, Lee YI, Kim NS, Kim DG, Yu DY, Moon HB and Park SK: Human hepatitis B virus-X protein alters mitochondrial function and physiology in human liver cells. J Biol Chem 279: 15460-15471, 2004.

4. Tan C, Guo H, Zheng M, Chen Y and Huang W: Involvement of mitochondrial permeability transition in hepatitis B virus replication. Virus Res 145: 307-311, 2009.

5. Shirakata $Y$ and Koike K: Hepatitis B virus $X$ protein induces cell death by causing loss of mitochondrial membrane potential. J Biol Chem 278: 22071-22078, 2003.

6. Gearhart TL and Bouchard MJ: Replication of the hepatitis B virus requires a calcium-dependent $\mathrm{HBx}$-induced $\mathrm{G} 1$ phase arrest of hepatocytes. Virology 407: 14-25, 2010. 
7. Kim SJ, Khan M, Quan J, Till A, Subramani S and Siddiqui A: Hepatitis B virus disrupts mitochondrial dynamics: Induces fission and mitophagy to attenuate apoptosis. PLoS Pathog 9: e1003722, 2013

8. Zhao B, Cao JF, Hu GJ, Chen ZW, Wang LY, Shangguan XX, Wang LJ, Mao YB, Zhang TZ, Wendel JF and Chen XY: Core cis-element variation confers subgenome-biased expression of a transcription factor that functions in cotton fiber elongation. New Phytol 218: 1061-1075, 2018.

9. Sato N: Central role of mitochondria in metabolic regulation of liver pathophysiology. J Gastroenterol Hepatol 22 (Suppl 1): S1-S6, 2007.

10. Varanasi L and Hosler JP: Subunit III-depleted cytochrome $c$ oxidase provides insight into the process of proton uptake by proteins. Biochim Biophys Acta 1817: 545-551, 2012.

11. Hosler JP: The influence of subunit III of cytochrome $c$ oxidase on the D pathway, the proton exit pathway and mechanism-based inactivation in subunit I. Biochim Biophys Acta 1655: 332-339, 2004.

12. Jung SY and Kim YJ: C-terminal region of $\mathrm{HBx}$ is crucial for mitochondrial DNA damage. Cancer Lett 331: 76-83, 2013.

13. Clippinger AJ and Bouchard MJ: Hepatitis B virus HBx protein localizes to mitochondria in primary rat hepatocytes and modulates mitochondrial membrane potential. J Virol 82: 6798-6811, 2008.

14. Li D, Ding J, Chen Z, Chen Y, Lin N, Chen F and Wang X: Accurately mapping the location of the binding site for the interaction between hepatitis B virus $\mathrm{X}$ protein and cytochrome $c$ oxidase III. Int J Mol Med 35: 319-324, 2015.

15. Zou LY, Zheng BY,Fang XF, Li D, Huang YH, Chen ZX, Zhou LY and Wang XZ: HBx co-localizes with COXIII in HL-7702 cells to upregulate mitochondrial function and ROS generation. Oncol Rep 33: 2461-2467, 2015

16. Zheng BY, Fang XF, Zou LY, Huang YH, Chen ZX, Li D Zhou LY, Chen H and Wang XZ: The co-localization of HBx and COXIII upregulates COX-2 promoting HepG2 cell growth. Int J Oncol 45: 1143-1150, 2014

17. Jaeschke H: Reactive oxygen and mechanisms of inflammatory liver injury: Present concepts. J Gastroenterol Hepatol 26 (Suppl 1): S173-S179, 2011.

18. Wang JH, Yun C, Kim S, Lee JH, Yoon G, Lee MO and Cho H: Reactive oxygen species modulates the intracellular level of $\mathrm{HBx}$ viral oncoprotein. Biochem Biophys Res Commun 310: 32-39, 2003.

19. Tang B, Tang F, Wang Z, Qi G, Liang X, Li B, Yuan S, Liu J, $\mathrm{Yu}$ S and $\mathrm{He} \mathrm{S}$ : Upregulation of Akt/NF- $\mathrm{BB}$-regulated inflammation and Akt/Bad-related apoptosis signaling pathway involved in hepatic carcinoma process: Suppression by carnosic acid nanoparticle. Int J Nanomedicine 11: 6401-6420, 2016.

20. Luo LH, Li DM, Wang YL, Wang K, Gao LX, Li S, Yang JG, Li CL, Feng W and Guo H: Tim3/galectin-9 alleviates the inflammation of TAO patients via suppressing Akt/NF-kB signaling pathway. Biochem Biophys Res Commun 491: 966-972, 2017.

21. Czaja MJ: Cell signaling in oxidative stress-induced liver injury. Semin Liver Dis 27: 378-389, 2007.

22. Zhu M, Guo J, Li W, Xia H, Lu Y, Dong X, Chen Y, Xie X, Fu S and $\mathrm{Li} \mathrm{M}$ : HBx induced AFP receptor expressed to activate PI3K/AKT signal to promote expression of Src in liver cells and hepatoma cells. BMC Cancer 15: 362, 2015.

23. Esmaeili MA, Farimani MM and Kiaei M: Anticancer effect of calycopterin via PI3K/Akt and MAPK signaling pathways, ROS-mediated pathway and mitochondrial dysfunction in hepatoblastoma cancer (HepG2) cells. Mol Cell Biochem 397: 17-31, 2014.

24. Wong VW, Yu J, Cheng AS, Wong GL, Chan HY, Chu ES, Ng EK, Chan FK, Sung JJ and Chan HL: High serum interleukin-6 level predicts future hepatocellular carcinoma development in patients with chronic hepatitis B. Int J Cancer 124: 2766-2770, 2009.

25. Huang YS, Hwang SJ, Chan CY, Wu JC, Chao Y, Chang FY and Lee SD: Serum levels of cytokines in hepatitis C-related liver disease: A longitudinal study. Zhonghua Yi Xue Za Zhi (Taipei) 62: 327-333, 1999.

26. Kakumu S, Okumura A, Ishikawa T, Yano M, Enomoto A, Nishimura H, Yoshioka K and Yoshika Y: Serum levels of IL-10, IL-15 and soluble tumour necrosis factor-alpha (TNF-alpha) receptors in type $\mathrm{C}$ chronic liver disease. Clin Exp Immunol 109: 458-463, 1997

27. Lee MO, Choi YH, Shin EC, Kang HJ, Kim YM, Jeong SY, Seong JK, Yu DY, Cho H, Park JH and Kim SJ: Hepatitis B virus $X$ protein induced expression of interleukin 18 (IL-18): A potential mechanism for liver injury caused by hepatitis B virus (HBV) infection. J Hepatol 37: 380-386, 2002.
28. Hu L, Wang C, Zhang Q, Yan H, Li Y, Pan J and Tang Z: Mitochondrial protein profile in mice with low or excessive selenium diets. Int J Mol Sci 17: pii: E1137, 2016.

29. Hong L, Wang X, Wu J and Cai W: Mitochondria-initiated apoptosis triggered by oxidative injury play a role in total parenteral nutrition-associated liver dysfunction in infant rabbit model. J Pediatr Surg 44: 1712-1718, 2009.

30. Paradies G, Ruggiero FM, Petrosillo G and Quagliariello E: Peroxidative damage to cardiac mitochondria: Cytochrome oxidase and cardiolipin alterations. FEBS Lett 424: 155-158, 1998.

31. Liu F, Song Y K and Liu D: Hydrodynamics-based transfection in animals by systemic administration of plasmid DNA. Gene Ther 6: 1258-1266, 1999.

32. Yang PL, Althage A, Chung J and Chisari FV: Hydrodynamic injection of viral DNA: A mouse model of acute hepatitis B virus infection. Proc Natl Acad Sci USA 99: 13825-13830, 2002.

33. Guo YJ, Wang W, Sun SH, Zeng DB, Zhao GY, Yu H, Guo Y, Tan WJ, Lu SC and Zhou YS: Immunosuppressant dexamethasone can significantly extend the expression of hepatitis B virus antigens in the HBV mouse model by hydrodynamic transfection method. Bing Du Xue Bao 26: 20-26, 2010 (In Chinese).

34. Tien Kuo M and Savaraj N: Roles of reactive oxygen species in hepatocarcinogenesis and drug resistance gene expression in liver cancers. Mol Carcinog 45: 701-709, 2006.

35. Cardin R, Piciocchi M, Bortolami M, Kotsafti A, Barzon L, Lavezzo E, Sinigaglia A, Rodriguez-Castro KI, Rugge $M$ and Farinati F: Oxidative damage in the progression of chronic liver disease to hepatocellular carcinoma: An intricate pathway. World J Gastroenterol 20: 3078-3086, 2014.

36. Heid ME, Keyel PA, Kamga C, Shiva S, Watkins SC and Salter RD: Mitochondrial reactive oxygen species induces NLRP3-dependent lysosomal damage and inflammasome activation. J Immunol 191: 5230-5238, 2013.

37. Waris G, Huh KW and Siddiqui A: Mitochondrially associated hepatitis B virus $\mathrm{X}$ protein constitutively activates transcription factors STAT-3 and NF-kappa B via oxidative stress. Mol Cell Biol 21: 7721-7730, 2001.

38. Chen WN, Liu LL, Jiao BY, Lin WS, Lin XJ and Lin X: Hepatitis B virus X protein increases the IL- $1 \beta$-induced NF- $\kappa B$ activation via interaction with evolutionarily conserved signaling intermediate in Toll pathways (ECSIT). Virus Res 195: 236-245, 2015.

39. Martindale JL and Holbrook NJ: Cellular response to oxidative stress: Signaling for suicide and survival. J Cell Physiol 192: $1-15,2002$.

40. Papaiahgari S, Yerrapureddy A, Hassoun PM, Garcia JG, Birukov KG and Reddy SP: EGFR-activated signaling and actin remodeling regulate cyclic stretch-induced NRF2-ARE activation. Am J Respir Cell Mol Biol 36: 304-312, 2007.

41. Lee YJ, Jeong HY, Kim YB, Lee YJ, Won SY, Shim JH, Cho MK, Nam HS and Lee SH: Reactive oxygen species and PI3K/Akt signaling play key roles in the induction of Nrf2-driven heme oxygenase-1 expression in sulforaphane-treated human mesothelioma MSTO-211H cells. Food Chem Toxicol 50: 116-123, 2012.

42. Wang P, Gao YM, Sun X, Guo N, Li J, Wang W, Yao LP and Fu YJ: Hepatoprotective effect of 2'-O-galloylhyperin against oxidative stress-induced liver damage through induction of Nrf2/ARE-mediated antioxidant pathway. Food Chem Toxicol 102: 129-142, 2017.

43. Ha HL and Yu DY: HBx-induced reactive oxygen species activates hepatocellular carcinogenesis via dysregulation of PTEN/Akt pathway. World J Gastroenterol 16: 4932-4937, 2010.

44. Su Q, Schröder CH, Hofmann WJ, Otto G, Pichlmayr R and Bannasch P: Expression of hepatitis $B$ virus $X$ protein in HBV-infected human livers and hepatocellular carcinomas. Hepatology 27: 1109-1120, 1998.

45. Lara-Pezzi E, Armesilla AL, Majano PL, Redondo JM and López-Cabrera M: The hepatitis B virus X protein activates nuclear factor of activated T cells (NF-AT) by a cyclosporin A-sensitive pathway. EMBO J 17: 7066-7077, 1998.

46. Lara-Pezzi E,Majano PL,Gómez-Gonzalo M, García-Monzón C, Moreno-Otero R, Levrero M and López-Cabrera M: The hepatitis B virus $X$ protein up-regulates tumor necrosis factor alpha gene expression in hepatocytes. Hepatology 28: 1013-1021, 1998.

47. Xiang WQ, Feng WF, Ke W, Sun Z, Chen Z and Liu W: Hepatitis $B$ virus $X$ protein stimulates IL-6 expression in hepatocytes via a MyD88-dependent pathway. J Hepatol 54: 26-33, 2011. 
48. Quétier I, Brezillon N, Duriez M, Massinet H, Giang E, Ahodantin J, Lamant C, Brunelle MN, Soussan $P$ and Kremsdorf D: Hepatitis B virus HBx protein impairs liver regeneration through enhanced expression of IL- 6 in transgenic mice. J Hepatol 59: 285-291, 2013.

49. Wang DY, Zou LP, Liu XJ, Zhu HG and Zhu R: Chemokine expression profiles of human hepatoma cell lines mediated by hepatitis B virus X protein. Pathol Oncol Res 22: 393-399, 2016.

50. Xia L, Tian D, Huang W, Zhu H, Wang J, Zhang Y, Hu H, Nie Y, Fan D and Wu K: Upregulation of IL-23 expression in patients with chronic hepatitis $B$ is mediated by the $\mathrm{HBx} / \mathrm{ERK} / \mathrm{NF}-\kappa \mathrm{B}$ pathway. J Immunol 188: 753-764, 2012.

51. Ehling J and Tacke F: Role of chemokine pathways in hepatobiliary cancer. Cancer Lett 379: 173-183, 2016.

52. Li XP, Yang XY, Biskup E, Zhou J, Li HL, Wu YF, Chen ML and Xu F: Co-expression of CXCL8 and HIF-1 $\alpha$ is associated with metastasis and poor prognosis in hepatocellular carcinoma. Oncotarget 6: 22880-22889, 2015.
53. Tangkijvanich $\mathrm{P}$, Thong-Ngam $\mathrm{D}$, Mahachai $\mathrm{V}$, Theamboonlers $\mathrm{A}$ and Poovorawan Y: Role of serum interleukin-18 as a prognostic factor in patients with hepatocellular carcinoma. World J Gastroenterol 13: 4345-4349, 2007.

54. Mohran ZY, Ali-Eldin FA and Abdel Aal HA: Serum interleukin-18: Does it have a role in the diagnosis of hepatitis $C$ virus related hepatocellular carcinoma? Arab J Gastroenterol 12: 29-33, 2011

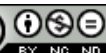

This work is licensed under a Creative Commons Attribution-NonCommercial-NoDerivatives 4.0 International (CC BY-NC-ND 4.0) License. 